\title{
Computer model of the power system with inclusion of a heat pump in the process of separation
}

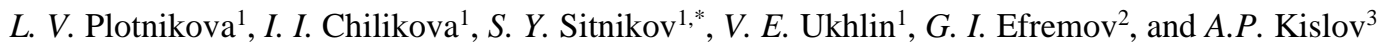 \\ ${ }^{1}$ Kazan State Power Engineering University, Kazan, Russia \\ ${ }^{2}$ Moscow Technological Institute, Moscow, Russia \\ ${ }^{3}$ S. Toraighyrov Pavlodar State University, Pavlodar, Kazakhstan
}

\begin{abstract}
The results of computer simulation of industrial processes of separation of substances with the inclusion of a heat pump are presented. Designs of heat pumps of closed type, open type, like "pipe in pipe" are considered. In the simulation software Aspen HYSYS, the adequacy of the computer model of the "rectification unit - closed type heat pump" system was checked. The results of computer simulation of the "rectification unit - open-type heat pump 'pipe in pipe'" system are presented. This system allows to increase the efficiency of the unit by $9 \%$ compared with the system of separation of substances with the inclusion of an open-type heat pump and by $14 \%$ compared with a system with the inclusion of a closedtype heat pump.
\end{abstract}

\section{Introduction}

A variety of organic polymers have been used as The processes of separation of substances, implemented in technological schemes of chemical, petrochemical, oil refining, pulp and paper, food and other industries, are characterized by significant energy consumption. Common technologies, involving separation processes are areas of separation of blend "ethylene-ethane", "propylene-propane" in the production of organic synthesis; areas of separation of the blend "propanebutane" at gas fractionation plants at the enterprises of primary oil refining; areas of separation of the blend "water-alcohol" in the pulp and paper and food industries and so on. In these areas, substances are separated by an absorption-rectification or condensation-rectification method. Such methods involve the use of a significant number of distillation columns, which are large recipients of thermal energy in the form of water vapor or hot water to heat these columns. In this regard, the issue of reducing energy consumption in the rectification systems [1-3].

It is proposed to reduce the energy intensity of separation processes by using own energy saving reserves. Namely, a system is proposed for utilization of the energy flow of the products of the distillation columns using heat pumps (HP) (figure 1) [4, 5]. The use of HP in the process of separation of substances allows, in addition to reducing consumption of thermal energy, to reduce the number of plates by changing the pressure in the columns and reduce the metal structure $[6,7]$.

\section{Theoretical part}

As utilization units for the separation of substances, heat pumps of a closed cycle (figure 1 (a)) and heat pumps of an open cycle (figure 1 (b)) can be used. In open-type HP, a column product is used as an intermediate coolant instead of freon. Analysis of options for separation schemes with the inclusion of HP of various types, showed that the most energy-efficient is the system "distillation column - open type heat pump" [6-8]. In this regard, it is proposed to further improve the energy system of substances separation with the inclusion of $\mathrm{HP}$, in the form of a "tube in tube" heat exchanger (figure 2) [9 - 11].

The unit (figure 2) works as follows: The initial blend is fed through the heat exchanger-heater 1 from below to the tube space of the column 2 . This also enter vapor-liquid blend from the upper part of the annular space of the column 2, passing through the heat exchanger 3 and the compressor 4, driven in rotation by the motor and creates an increased pressure and temperature in the pipe space of the column 2. The vapors rising in the tube space of column 2 are in contact with the reflux, flowing downward and are enriched in a volatile component. They are removed from the top of the column 2, condensed in the distiller 5 and come partially in the form of reflux into the upper part of the column 2, and partly in the form of the distillate. The vapor-liquid blend from the bottom of the column 2 under pressure passes the heat exchanger 3 and expander 6 , where it is throttled, giving its energy to the rotation of the compressor, and enters the annular space of the column 2 for irrigation. The annular space of the column 2 to increase the contact surface of the vapor and liquid

\footnotetext{
* Corresponding author: ssitnikov@ mail.ru
} 


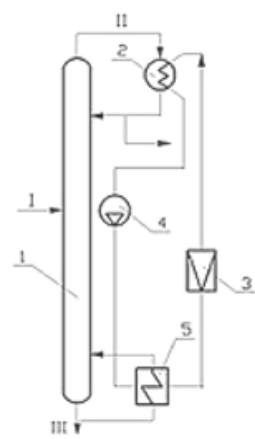

(a)

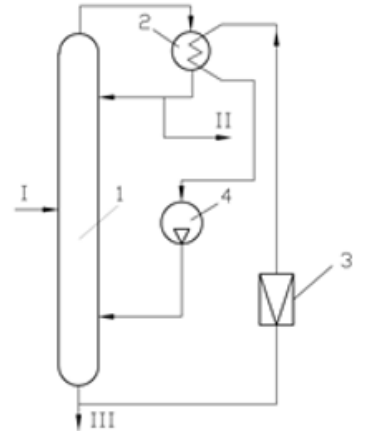

(b)

Fig. 1. Inclusion of a closed-loop heat pump (a) and an open-cycle heat pump (b) in a distillation unit: 1 - rectification column; 2 - dephlegmator evaporator; 3 - throttle valve; 4 - compressor; 5 - boiler condenser; I- the divided mix; II - the top product; III - lower product.
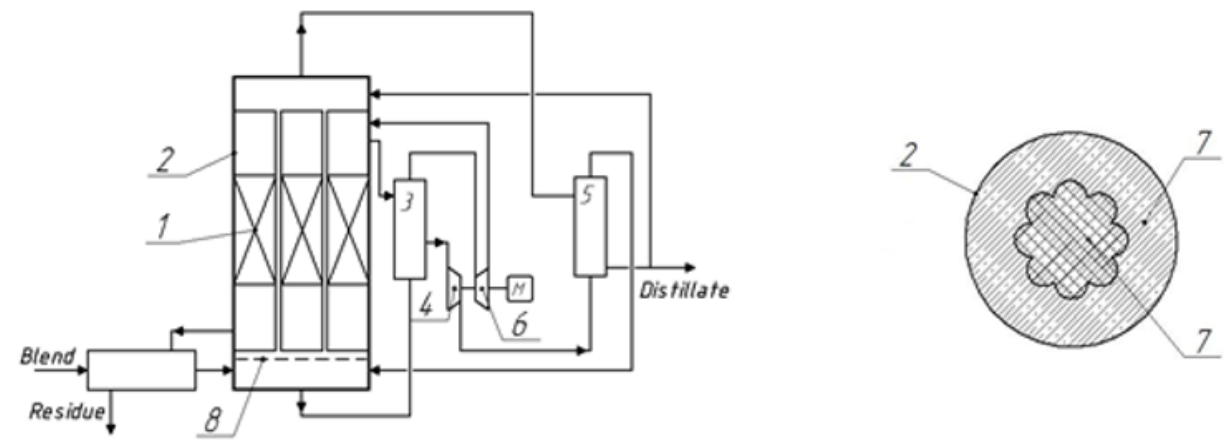

Fig. 2. Distillation column with a heat pump in the form of a heat exchanger "pipe in pipe": 1 - heat exchanger-heater, 2 distillation column, 3 - heat exchanger, 4 - compressor, 5 - distiller, 6 - expander, 7 - nozzle, 8 - grid; M - motor.

phases is filled behind the nozzle 7. Heating of the vapor-liquid mixture in the annular space of the column 2 occurs due to the transfer of heat from the tube space through the pipe walls, thus eliminating the need for a cube of the column and the supply of heat into it. The vapors from the upper part of the annular space of the column 2 pass through the heat exchanger 3 , where they are heated by the vapors leaving the pipe space of the column. Coming out of the lower part of the annular space of the column 2 , the residue transfers its heat to the heating of the initial blend in the heat exchanger preheater 1 .

\section{Practical part}

Modeling and comparative analysis of the energy efficiency of the processes of separation of substances with the inclusion of a heat pump of a closed type, open type and "pipe in pipe" type was conducted in software Aspen HYSYS using the example of the substances separation system of "propane-butane". Aspen HYSYS is designed for computer simulation of operating modes of systems, including separation units and heat and mass transfer equipment. Unlike a number of specialized software products, Aspen HYSYS allows you to make changes to models of known designs of technological installations [12-15]. In this regard, Aspen HYSYS is a convenient device for modeling new designs of the "rectification column - heat pump" systems.
First, a computer model of the "rectification unit closed type heat pump" system was built at Aspen HYSYS. This system was previously calculated for propane-butane substances, and its computer model was previously built in the CHEMCAD software [8]. Figure 3 and Figure 4 show program windows that demonstrate the assembly of system elements and data entry, respectively. Data used: column type T-100 (propanebutane separation columns for the gas fractionation section of the Achinsk oil refinery of the Vostok Oil Company), the number of plates of the column is 60 , the temperature of the top of the column is $70{ }^{\circ} \mathrm{C}$, the temperature of the bottom of the column is $120{ }^{\circ} \mathrm{C}$.

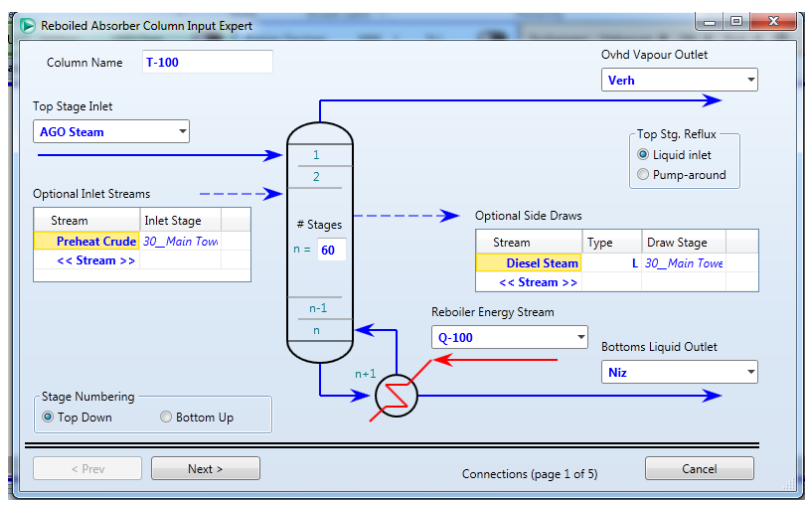

Fig. 3. Building the structure of the system and entering the geometric characteristics of the column in Aspen HYSYS. 


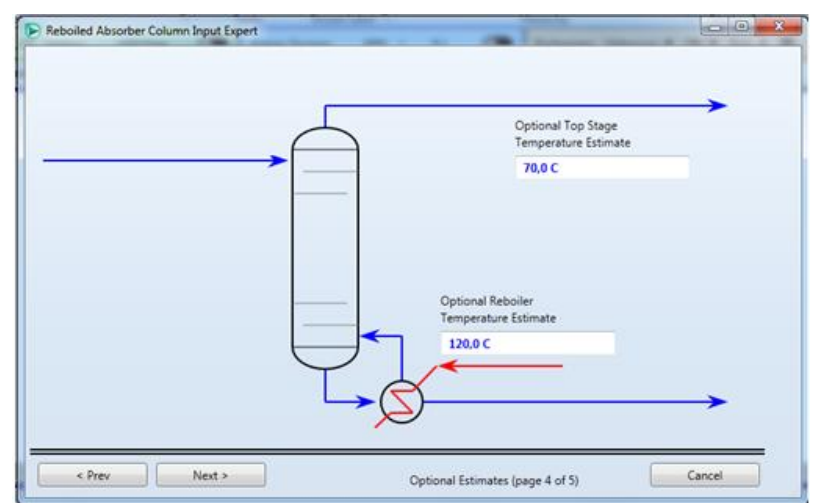

Fig. 4. Entering the temperature data of the top and bottom product of the column in Aspen HYSYS.

Comparison of the results of the computer model of the column in Aspen HYSYS with the results of calculations obtained earlier in the CHEMCAD software [8] is presented in table 1 . The parameters are close, so this computer model can be considered adequate and can be used as a basis for building a computer model of an upgraded open installation of the "pipe in pipe" type.

Table 1. Comparison in the parameters of the computer model of the column in Aspen HYSYS and in CHEMCAD.

\begin{tabular}{|c|c|c|}
\hline Parameter & Hysys & ChemCAD \\
\hline Temperature ${ }^{\circ} \mathrm{C}$ & 110 & 110 \\
\hline Pressure, $\mathrm{kg} / \mathrm{cm}^{2}$ & 5.3 & 5.3 \\
\hline Molar flow, $\mathrm{kg} \cdot \mathrm{mol} / \mathrm{h}$ & 1495 & 1502 \\
\hline Mass flow, $\mathrm{kg} / \mathrm{h}$ & 353094 & 352998 \\
\hline $\begin{array}{c}\text { Standard ideal volume } \\
\text { flow rate, } \mathrm{m}^{3} / \mathrm{h}\end{array}$ & 600 & 600 \\
\hline $\begin{array}{c}\text { Molar enthalpy, } \mathrm{kcal} / \\
\mathrm{kg} \cdot \mathrm{mol}\end{array}$ & -13378 & - \\
\hline $\begin{array}{c}\text { Molar entropy, } \mathrm{kJ} / \\
\mathrm{kg} \cdot \mathrm{mol} \cdot \mathrm{C}\end{array}$ & -100700 & - \\
\hline $\begin{array}{c}\text { Molar density, } \mathrm{kg} \cdot \mathrm{mol} / \mathrm{m}^{3} \\
\text { Mass density, } \mathrm{kg} / \mathrm{m}^{3}\end{array}$ & 0.859 & 0.88 \\
\hline $\begin{array}{c}\text { Volume flow, } \mathrm{m}^{3} / \mathrm{h} \\
\text { Mass enthalpy, } \mathrm{kcal} / \mathrm{kg}\end{array}$ & -562.88 & 205.69 \\
\hline $\begin{array}{c}\text { Mass entropy, } \mathrm{kJ} / \mathrm{kg} \cdot \mathrm{C} \\
\text { Thermal power, } \mathrm{kJ} / \\
\mathrm{kg} \cdot \mathrm{mol} \cdot \mathrm{C}\end{array}$ & -426.38 & 1761 \\
\hline
\end{tabular}

Further, on the basis of this model of the "rectification column - closed type heat pump" system, a model of the "rectification column - open type heat pump" system was built. The fact that an unit with open type HP is more energy efficient follows from table for 2. The final design of these models in the Aspen HYSYS is presented in Figure 5 and Figure 6.

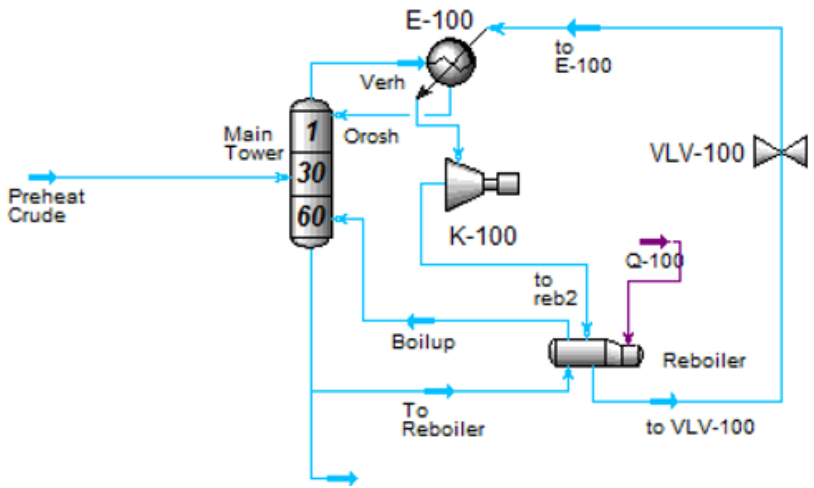

Fig. 5. Model of the system "Distillation column - HP closed type" in Aspen HYSYS.

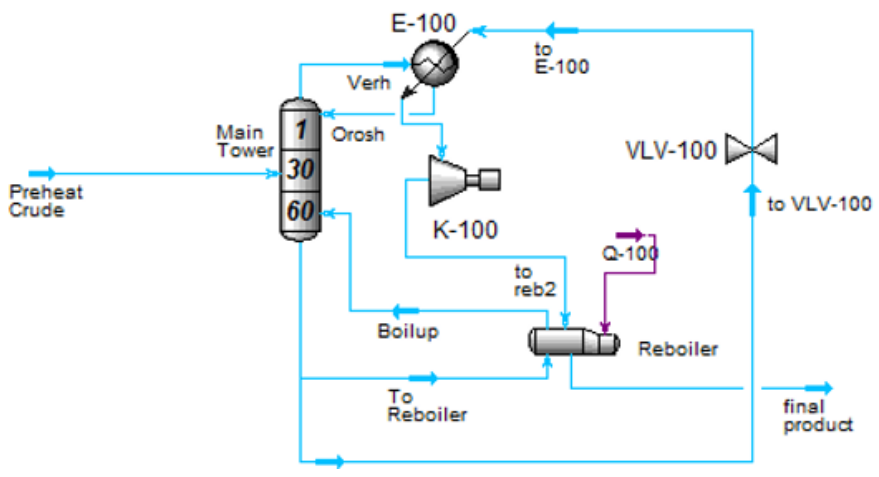

Fig. 6. "Rectification Column - HP open type" system model in Aspen HYSYS.

Based on these results, a simulation of the "rectification unit - HP open type 'pipe in pipe'"system was made (Figure 7).
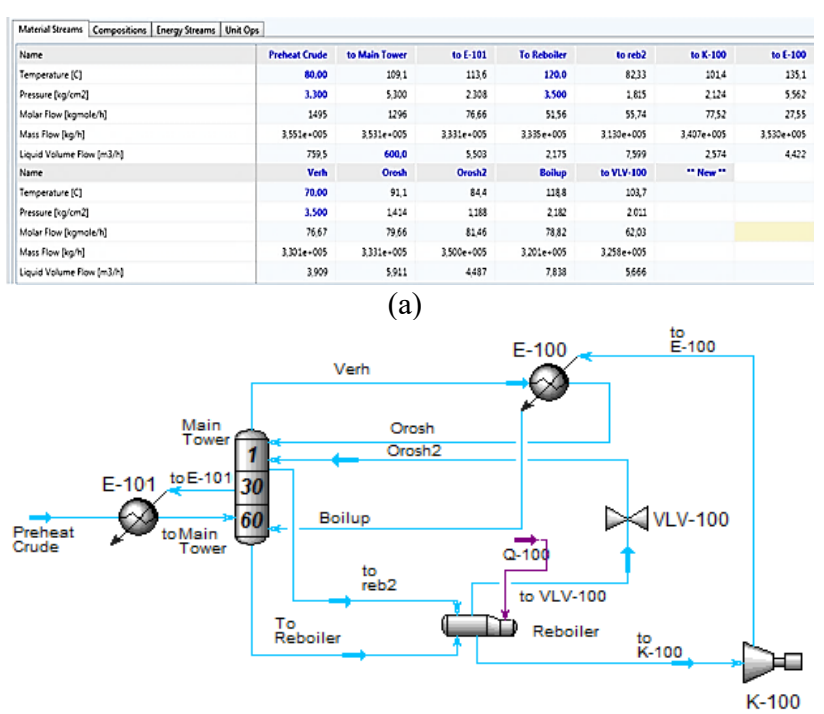

(b)

Fig. 7. "Rectification Column - HP Open Type" system model in Aspen HYSYS: unit operation parameters (a) and model structure (b).

\section{Results}

The system modeling results with the inclusion of HP of various types are presented in table 2 . From table 2 it 
Table 2. System simulation results with various types of HP included.

\begin{tabular}{|c|c|c|c|c|}
\hline \multicolumn{2}{|l|}{ Parameter } & HP closed type & HP open type & $\begin{array}{l}\text { HP open type "pipe in } \\
\text { pipe" }\end{array}$ \\
\hline \multicolumn{2}{|l|}{ Adiabatic compressor efficiency } & 0.631 & 0.645 & 0.711 \\
\hline \multirow{2}{*}{$\begin{array}{l}\text { Specific heat loads at HP nodes, } \\
\mathrm{kJ} / \mathrm{kg}\end{array}$} & evaporator & 300 & 310 & 345 \\
\hline & condenser & 426 & 418.36 & 394.2 \\
\hline \multicolumn{2}{|l|}{ Work compression, $\mathrm{kJ} / \mathrm{kg}$} & 126.6 & 108.36 & 49.21 \\
\hline \multicolumn{2}{|l|}{ Heat load HP, $\mathrm{kJ} / \mathrm{kg}$} & 426.6 & 418,36 & 394.2 \\
\hline \multicolumn{2}{|c|}{ Energy consumed by an electric motor, $\mathrm{kJ} / \mathrm{kg}$} & 166.6 & 138,22 & 62.77 \\
\hline \multicolumn{2}{|c|}{ Heat conversion coefficient } & 3.36 & 3,96 & 8.01 \\
\hline \multicolumn{2}{|l|}{ Power conversion ratio } & 2.64 & 3,02 & 6.28 \\
\hline \multicolumn{2}{|c|}{ Specific consumption of primary energy } & 1.02 & 0.89 & 0.43 \\
\hline \multicolumn{2}{|c|}{ The degree of pressure increase in the compressor } & 5.71 & 5.714 & 5.714 \\
\hline \multicolumn{2}{|c|}{ Exergetic efficiency HP } & 0.62 & 0.67 & 0.76 \\
\hline
\end{tabular}

follows that due to the change of the inclusion scheme in separation unit the open-type HP with non-standard design, the heat load of the heat pump and the energy consumption by the electric motor are reduced.

Due to this, the heat conversion coefficient, the electricity conversion ratio has increased. The efficiency of the heat pump increased by $9 \%$ compared with the standard open-type separation scheme.

The developed computer model can be used in the future to assess the results of field experiments. Also, the obtained data on the possibility of using various types of transformers of thermal energy, the conditions for their inclusion in the synthesized energy recovery systems can be used when considering the possibility of using heat pumps for heating enterprises, as well as in energyintensive processes of drying, concentration, evaporation, and other things in various industries with secondary energy resources.

\section{References}

[1] Laptev A G, Farakhov $\mathrm{T} M$ and Basharov M M 2016 "Processes and apparatuses of chemical technologies: modeling and modernization of industrial desulfurizing packed columns at refineries" Chem. and tech. of fuels and oils 52 (5) 472-479

[2] Laptev A G, Farakhov M I and Basharov M M 2014 Improving the Efficiency of Gas-Separation Units in Ethylene Production Chem. and Petrol. Eng. 50(7-8) $5 \mathrm{p}$

[3] Yang A, Jin S, Shen W, Chien I-L and Ren J 2019 Investigation of energy-saving azeotropic dividing wall column to achieve cleaner production via heat exchanger network and heat pump technique $\mathrm{J}$. of $\mathrm{Cl}$. Prod. 234, 410-422

[4] Plotnikova L V, Kostyleva E E, Chilikova I I and Sitnikov S Y 2019 The use of heat pump installations as part of waste energy convertion complexes in the joint generation of electrical and thermal energy IOP Conf. Series: Earth and Environmental Science, Int. Scientific Conf. "Efficient waste treatment - 2018" (13-14 December, 2018) p. 012067

[5] Kladov I V, Sedlov A S, Shelginsky AYa and Galaktionov V V 2012 "Analysis of the efficiency of using open-type electric pump systems with electric drive in the production of phosphoric acid extraction" El. Equip.: operat. and rep. 6, 13-17

[6] Krasavina E O and Plotnikova L V 2016 Energy-saving heat pump in industrial separation systems Bull. of Kaz. St. Power Eng. Un. 4 (32) 95-105

[7] Plotnikova L V, Efremov G I, Sitnikov S Y and Chilikova I I 2019 Energy-resource-saving system "distillation unit - heat pump" for industrial separation of substances 2018 Int. Multi-Conf. on Industrial Engineering and Modern Technologies, FarEastCon 2018. (Vladivostok: Far Eastern Federal University) p 8602494

[8] Plotnikova L.V. Chilikova I.I. Valiev R.N. Uhlin V.E. Kantyukov R R, Lebedev R V, Shenkarenko S V 2018 Organization of a system for converting secondary thermal energy using heat pump equipment for an oil refinery of the eastern oil company Terr. "Neftegaz" 1120 - 24

[9] Plotnikova L V, Chilikova I I, Sitnikov S Y and Efremov G I 2016 Systematic approach to the assessment of energy complex efficiency for thermal energy production with heat power saving transformer turning on Int. J. of Pharm. and Tech. 8 (4) 26727-37

[10] Efremov G I and Pinskiy M E 1997 "On the calculation of the rectification of organic solvents in the processes of fabric finishing" Izv. Vyssh. Uch. Zav. Tech. of the textile ind. 3103

[11] Aleksandrov I A, Efremov G I and Bryuzginov E V 2007 Application of a heat pump in rectification processes Energy sav. and water treat. 1, 3336

[12] Ostrovsky G M, Lapteva T V, Ziyatdinov N N and Silvestrova A S 2017 Design of Chemical Engineering Systems with Chance Constraints Theor. Found. of Chem. Eng. 51(6) 961-971

[13] Ostrovsky G M, Ziyatdinov N N, Lapteva T V, Silvestrova A S, Nguyen Q T 2017 Optimization of 
Chemical Process with Joint Chance Constraints Ind. and Eng. Chem. Res. 56(12) 3309-3331

[14] Ostrovsky G M, Lapteva T V and Ziyatdinov N N 2014 Optimal design of chemical processes under uncertainty Theor. Found. of Chem. Eng. 48(5) 583-593

[15] Ostrovskii G M, Ziyatdinov N N, Lapteva T $\mathrm{V}$ and Bogula N Y 2010 Optimal design of a system of distillation columns Dokl. Chem. 431(2) 116-119 